\title{
Do Doubly Charged Monatomicanions Exist in Aqueous Solutions?
}

\author{
*Yizhak Marcus \\ Institute of Chemistry, The Hebrew University of Jerusalem, Israel
}

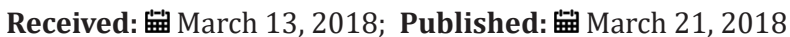

*Corresponding author: Yizhak Marcus, Institute of Chemistry, The Hebrew University of Jerusalem, Israel, Email: ymarcus@vms.huji.ac.il

\section{Introduction}

The chalcogenide atoms ( $\mathrm{X}=$ oxygen, sulfur, selenium, tellurium, polonium) form doubly charged monatomic anions, $\mathrm{X}^{2-}$, which exist in crystalline salts. The question arises whether, once such salts are dissolved in water, such species persist, or do they hydrolyze completely to form the hydrochalcogenide anion:

$$
\mathrm{X}^{2-}+\mathrm{H}_{2} \mathrm{ODHX} \mathrm{X}^{-}+\mathrm{OH}^{-}
$$

It is clear that in the case of oxygen this reaction proceeds to the right to completion: $\mathrm{O}^{2-}+\mathrm{H}_{2} \mathrm{O} \rightarrow 2 \mathrm{OH}^{-}$. Recently it was shown that also in the case of sulfur the anion S2- does not exist in aqueous solutions [1]. In attempts to push reaction (1) backwards by the addition of massive quantities (high concentrations) of hydroxyl ions, the necessarily added cations (say, $\mathrm{Na}^{+}$)associate with the sulfide anion, yielding the ion pairs $\left(\mathrm{NaS}\left(\mathrm{H}_{2} \mathrm{O}\right) \mathrm{p}-\right)$, but not $\mathrm{S}\left(\mathrm{H}_{2} \mathrm{O}\right)$ ${ }_{n}{ }^{2-}$. On the other hand, spectroscopic evidence shows that the corresponding addition of $\mathrm{CsOH}$ does not yieldthe hydrated sulfide dianions either. It was concluded that the doubly charged hydrated sulfide anions $\mathrm{S}\left(\mathrm{H}_{2} \mathrm{O}\right)_{n}{ }^{2-}$ do not exist.

It is therefore of interest to examine whether the reported evidence related to the existence of hydrated selenide $\mathrm{Se}\left(\mathrm{H}_{2} \mathrm{O}\right)$ ${ }_{n}^{2-}$ and telluride $\mathrm{Te}\left(\mathrm{H}_{2} \mathrm{O}\right)_{n}{ }^{2-}$ anions in aqueous solutions can be reinterpreted in terms that negate their existence.

The evidence concerning the aqueous selenide and telluride dianions pertains to calculations of the second dissociation constant of hydrogen selenide and telluride or the dissociation constant of the aqueous hydroselenide and hydrotelluride anions, $\mathrm{K}_{2}$ :

$$
\mathrm{HSe}\left(\mathrm{H}_{2} \mathrm{O}\right)_{q}^{-}\left(\operatorname{orHTe}\left(\mathrm{H}_{2} \mathrm{O}\right)_{q}^{-}\right)+\mathrm{OH}_{a q}{ }^{-} \mathrm{DSe}\left(\mathrm{H}_{2} \mathrm{O}\right)_{n}^{2-}\left(\mathrm{orTe}\left(\mathrm{H}_{2} \mathrm{O}\right)_{n}^{2-}\right)+\mathrm{H}_{2} \mathrm{O}
$$

The existence of the dianions $\mathrm{Se}^{2-}$ and $\mathrm{Te}^{2-}$ in aqueous solutions was assumed a priori in earlier publications as a matter of course. In the polarographic study of the anodic oxidation of $\mathrm{H}_{2} \mathrm{X}$ [2] it was stated that no experimental value of $K_{2}$ (for dissociation of $\mathrm{HSe}^{-}$ and $\left.\mathrm{HTe}^{-}\right)$was available, so a value was assumed $\left(10^{-14}\right.$ and $10^{-11}$, respectively) in order to fit the half-wave potentials up to $\mathrm{pH}=$ $13.9\left(1 \mathrm{M} \mathrm{NaOH}\right.$ ), but no fit was tried with the value $K_{2}=0$. For the telluride anion there was the added complication that the anodic oxidationresulted in the intermediate formation of elemental tellurium that yields theditelluride anion $\mathrm{Te}_{2}{ }_{2}^{2-}$, which is then further oxidized. In fact, the polarography of the ditelluridedianion was studied in [3] in aqueous $0.01,0.1$ and $1.0 \mathrm{M} \mathrm{NaOH}$ (translated to $\mathrm{pH}=12,13$, and 14) on the assumption that the disproportionation $\mathrm{Te}_{2}{ }^{2-} \mathrm{DTe}+\mathrm{Te}^{2-}$ takes place, but, again, the nature of the reduced telluride species was not established. What was established was that the polarographic electrode reaction corresponded to a two electron change: $\mathrm{H}_{2} \mathrm{TeDTe}+2 \mathrm{H}^{+}+2 e^{-}$.

In a subsequent examination of the Se(-II) case [4], the change of $\mathrm{pH}$ of $0.2 \mathrm{M}$ aqueous $\mathrm{KOH}$ on addition of $\mathrm{H}_{2} \mathrm{Se}$ was interpreted as the formation of $\mathrm{HSe}^{-}+\mathrm{Se}^{2-}$, the latter constituting $8 \%$ of the total dissolved selenium. Conversion of $\mathrm{pH}$ values obtained with a glass electrode in mildly alkaline solutions to actual concentrations of the hydroxide anion is problematic, however, and avoidance of the assumption of $\mathrm{Se}^{2-}$ in solution could yield the same change in $\mathrm{pH}$ as that measured. The solubility of $\mathrm{Na}_{2}$ Se measured in [4] in aqueous $\mathrm{NaOH}$ solutions in the presence of high concentrations of $\mathrm{Na}^{+}$ions ( $4.31 \mathrm{~m}$, but their source was not specified), was interpreted by inclusion of $\mathrm{Se}^{2-}$ species, but the formation of the $\mathrm{NaSe}^{-}$ion pairs was ignored. The complication of the formation of $\mathrm{Se}_{2}{ }^{2-}$ by partial oxidation was mentioned in this study.

An ultraviolet spectroscopy (charge transfer to solvent spectra) study of the selenide species [5] again assumed the presence of the aqueous $\mathrm{Se}^{2-}$ anions in 0.12 to $11.6 \mathrm{~m} \mathrm{NaOH}$ assigning to it and to HSe- anions specific absorption maxima. The wavelengths of these depended, however, on the ionic strength of the solutions, and shifts had to be taken into account. The possibility that $\mathrm{NaSe}^{-}$ ion pairs do occur but $\mathrm{Se}^{2-}$ species do not in the solutions wan not taken into account. In a later paper [6] it was stated that the second dissociation step:

$$
\mathrm{HSe}^{-} \mathrm{DH}^{+}+\mathrm{Se}^{2-}
$$


is completely shifted to the left at $\mathrm{pH}=12.3$, hence $\mathrm{Se}^{2-}$ does not play any role and fully reduced selenium appears only as the monoprotonated $\mathrm{HSe}^{-}$. However, the polyselenidedianion $\mathrm{Se}_{3}{ }^{2-}$ is a species that has to be taken into account.

The most recent study was that of the charge transfer to solvent ultraviolet spectra of telluride anions. The spectrum in $0.52 \mathrm{M} \mathrm{NaOH}$ was assigned to the $\mathrm{Te}^{2-}$ species, whereas in a $\mathrm{NH}_{3} / \mathrm{NH}_{4}{ }^{+}$buffer at $\mathrm{pH}>5$ and ionic strength of $0.01 \mathrm{M}$ the observed spectrum was assigned to $\mathrm{HTe}^{-}$. However, the possibility that $\mathrm{NaTe}^{-}$was formed in the $0.52 \mathrm{M} \mathrm{NaOH}$ solution and was responsible to the shift by the higher ionic strength of the $\mathrm{NaOH}$ solution in the direction of lower energies was not considered. Thus, there was no compelling reason to assign the spectrum in the $\mathrm{NaOH}$ solution to the dianion $\mathrm{Te}^{2-}$ species, and the assignment was due to the a priori assumption that such a species should exist in alkaline aqueous solutions [7]. Nothing appears to have been published regarding the polonium Po (-II) or polonide anion.

\section{Conclusion}

In conclusion, there is no compelling reason to interpret the experimental results concerning the chalcogenide X(-II) species as ultimately forming the $\left.\mathrm{X}_{2} \mathrm{H}_{2} \mathrm{O}\right)_{n}{ }^{2-}$ species by dissociation of the wellestablished $\mathrm{HX}\left(\mathrm{H}_{2} \mathrm{O}\right)_{q}^{-}$in highly alkaline solutions.

\section{References}

1. P M May, D Batka, G Hefter, E Konigsberger, D Rowland (2018) Goodbye to $\mathrm{S}^{2-} \mathrm{I}$ aqueous solution. Chem Commun Ahead of print.

2. J J Lingane, LW Niedrach (1948) Polarography of selenium and tellurium I The -2 states. J Am Chem Soc 70: 4115-4120.

3. A J Panson (1963) Polarography of the ditelluride anion. J Phys Chem 67(10): 2177-2180.

4. R H Wood (1958) The second ionization constant of hydrogen selenide. J Am Chem Soc 80(7): 1559-1562.

5. D E Levy, R J Myers (1993) Spectroscopic determination of the second dissociation constant of $\mathrm{H}_{2} \mathrm{Se}$ and the activity coefficients and spectral shifts of the ions. J Phys Chem 94: 7842-7847.

6. A Goldbach, M L Saboungi, J A Johnson, A Cook, D Meisel (2000) Oxidation of aqueous polyseledide solutions. A mechanistic pulse radiolysis study J Phys Chem A 104: 4011-4016.

7. $\mathrm{R}$ J Myers (2007) Second dissociation constant of $\mathrm{H}_{2} \mathrm{Te}$ and the absorption spectra of $\mathrm{HTe}^{-}, \mathrm{Te}^{2-}$, and $\mathrm{Te}_{2}{ }^{2-}$ in aqueous solution. J Solution Chem 36(3): 395-403.

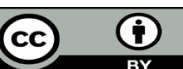

This work is licensed under Creative Commons Attribution 4.0 License

To Submit Your Article Click Here:

Submit Article

DOI: $10.32474 /$ AOICS.2018.02.000134

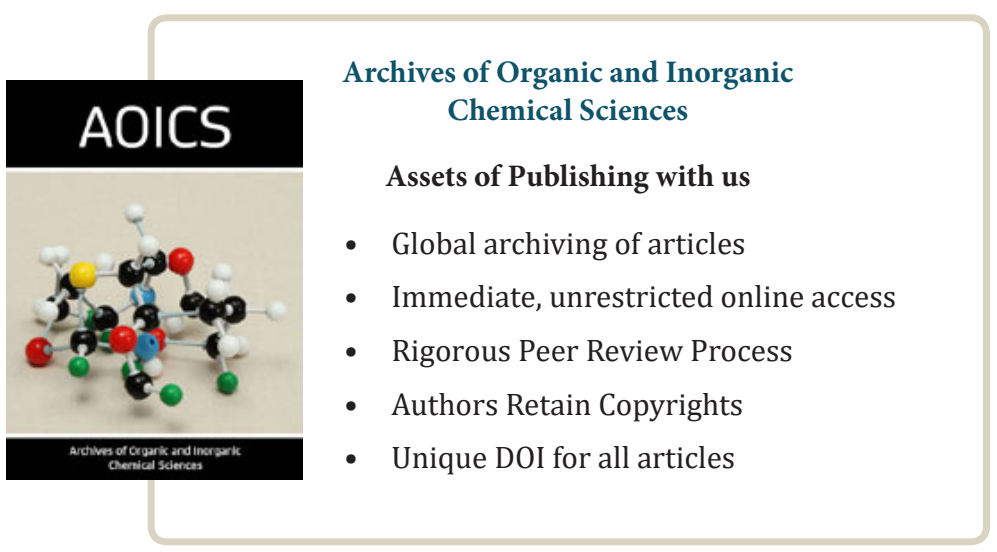

